\title{
Pregnancy protection of breast cancer: new insights reveal unanswered questions
}

\author{
Daniel Medina* \\ See related research by Meier-Abt et al., http://breast-cancer-research.com/content/15/2/R36
}

\begin{abstract}
The recent paper by Meier-Abt and colleagues on pregnancy protection of breast cancer development takes a different approach to the problem and focused on the effect of parity on the cell subpopulations of the mouse mammary gland. Their results demonstrate that parity decreases the cell number of the hormone receptor-positive luminal cells (that is, luminal Sca1+) but not the basal stem/progenitor cells (CD24lo/ CD49hi). Additionally, microarray studies demonstrate that wnt4 expression from the luminal Sca1+ cells is markedly reduced as is the wnt signaling pathway in basal cells. One important implication from these results is that targeting the wnt signaling pathway might be a feasible prevention approach in humans.
\end{abstract}

The recent paper by Meier-Abt and colleagues [1] on pregnancy protection of breast cancer development provides new insight into the mechanisms behind the protective effect. The decreased risk of breast cancer as a result of an early full-term pregnancy is a well-documented phenomenon in humans [2] and has been studied in multiple animal models [3]. The cellular and molecular changes resulting as a consequence of a full-term pregnancy are well documented in both animal models and humans [3-5]. Despite the abundant documentation of the effect of a full-term pregnancy over the past 40 years, the information has not been successfully translated to a clinical prevention paradigm.

Meier-Abt and colleagues [1] have taken a different approach to the problem and focused on the effect of parity on the cell subpopulations of the mouse mammary gland. The results are in many ways supportive of current concepts of pregnancy protection but have added the

*Correspondence: dmedina@bcm.edu

Department of Molecular and Cellular Biology, Baylor College of Medicine, One Baylor Plaza, Houston, Texas 77030, USA important knowledge of how pregnancy affects specific mammary cell subpopulations. They demonstrate quite convincingly that parity decreases the cell number of the hormone receptor-positive luminal cells (that is, luminal Sca1+) but not the basal stem/progenitor cells (CD24lo/ CD49hi). Importantly, microarray studies demonstrate that wnt4 expression from the luminal Sca1+ cells is markedly reduced as is the wnt signaling pathway in the basal population. Additionally, Notch signaling in the basal cells is increased. In all cell populations, including the basal cells, differentiation markers are increased by parity. One important conclusion from their results is that the wnt signaling pathway is disrupted, which results in the division potential of the basal cells being severely impaired and, consequently, a predicted decrease in tumorigenic potential. Additionally, the repopulation potential of the basal cells from parous mice was shown to be decreased compared to the same population from age-matched virgin mice in an in vivo limiting dilution assay. One important implication from these results is that targeting the wnt signaling pathway might be a feasible prevention approach in humans. Of course, it will be important to demonstrate directly that this pathway has a causative role in a model of pregnancymediated protection.

Several important questions remain to be answered in our understanding of the cellular and molecular basis for parity-induced protection. First, the cell subpopulation that is the target for the initiation event that results in development of the cancer is not clear in any animal model and surely not in human. Thus, it is unknown if it is the basal stem cell or the alveolar progenitor cell that is the target for the oncogenic initiating event. Second, although the limiting dilution assay applied to subpopulations of the mammary epithelial cells is a sensitive assay to detect repopulation potential of cells, the assay itself has limitations. The assay has little relevance to the normal physiology of the mammary gland with respect to either turnover of the mammary cells during the estrus cycle or during pregnancy. The dynamics of mammary cell function, both differentiation activity and cell division activity, is a reflection of the cell-cell interactions. 
These include duct/alveoli cellular interactions as well as cell/microenvironment interactions [6]. The results of Meier-Abt and colleagues [1] illustrate this concept very nicely since decreases in cell number and specific gene expression are detected in the hormone receptor-positive cells and also the alteration of wnt signaling detected in the basal cells, which appears to be a consequence of the decreased wnt expression in the hormone receptorpositive cells. Since there is a clear cell-cell interaction in this pathway, what would be the result if one tested the repopulation ability of combined selected cell populations (that is, luminal (Sca1 positive) and basal cells)? It might reveal the repopulation frequency decrease from 1 in 500 cells to 1 in 100 cells as seen in several earlier experiments [7,8]. Additionally, with reporter labeled cells, one would be able to determine the cell that repopulates the gland under more normal physiological conditions. Recently, it has been demonstrated by lineage tracing that both the luminal cell and the basal cell generate the cells in their respective layers [9]. This is in accordance with the observations of others that, in pregnancy, the cell that generates the large expansion in cell number is the alveolar (lobular) progenitor cell, not the basal stem cell [10].

The role of the basal stem cell in normal mammary cell function and development is not well understood, particularly in the adult mammary gland. Although some studies suggest that pregnancy alters the stem cell population [11], other studies do not support this idea [12,13]. Indeed, using the serial transplantation assay to measure repopulation potential and replication life span, experiments have demonstrated there is no difference in these properties between stem cells taken from old multiparous and nulliparous mice [13]. A limiting dilution assay showed the same results as the serial transplantation assay [12,13]. The studies by Meier-Abt and colleagues [1] are important as they emphasize the critical interactions of the cell subpopulations and indicate that these interactions are important for proper interpretation of normal and neoplastic development in the mammary gland.

It is clear that as we understand more about the interactions of the different cell compartments of the mammary gland and the importance of the microenvironment in both the normal physiology of the gland and the tumorigenic process, we will have greater opportunities to target specific pathways. The results of Meier-Abt and colleagues [1] provide deeper understanding of the role of parity as well as identify new potential targets for prevention therapies.

\section{Competing interests}

The author declares that they have no competing interests.

Published: 8 May 2013

\section{References}

1. Meier-Abt F, Milani E, RoloffT, Brinkhaus H, Duss S, Meyer DS, Klebba I, Balwierz PJ, van Nimwegen E, Bentires-Alj M: Parity induces differentiation and reduces Wnt/Notch signaling ratio and proliferation potential of basal stem/progenitor cells isolated from mouse mammary epithelium. Breast Cancer Res 2013, 15:R36.

2. MacMahon B, Cole P, Lin TM, Lowe CR, Mirra AP, Ravnihar B, Salber EJ, Valaoras VG, Yuasa S: Age at first birth and breast cancer risk. Bull World Health Org 1970, 43:209-221.

3. Medina D: Mammary developmental fate and breast cancer risk. Endocrine Related Cancer 2005, 12:1-13.

4. Blakely CM, Stoddard AJ, Belka GK, Dugan KD, Notarfrancesco KL, Moody SE, D'Cruz CM, Chodosh LA: Hormone-induced protection against mammary tumorigenesis is conserved in multiple rat strains and identifies a core gene expression signature induced by pregnancy. Cancer Res 2006, 66:6421-6431.

5. Peri S, de Cicco RL, Santucci-Pereira J, Slifker M, Ross EA, Russo IH, Russo PA, Arslan AA, Belitskaya-Lévy I, Zeleniuch-Jacquotte A, Bordas P, Lenner P,

Åhman J, Afanasyeva Y, Johansson R, Sheriff F, Hallmans G, Toniolo P, Russo J: Defining the genomic signature of the parous breast. BMC Med Genomics 2012, 5:46.

6. Bruno RD, Smith GH: Reprogramming non-mammary and cancer cells in the developing mouse mammary gland. Semin Cell Dev Biol 2012, 23:591-598.

7. Moraes RC, Zhang X, Harrington N, Fung JY, Wu MF, Hilsenbeck SG, Allred DC, Lewis MT: Constitutive activation of smoothened (SMO) in mammary glands of transgenic mice leads to increased proliferation, altered differentiation and ductal dysplasia. Development 2007, 134:1231-1242.

8. Smalley MJ, Kendrick H, Sheridan JM, Regan JL, Prater MD, Lindemann GJ, Watson CJ, Visvader JE, Stingl J: Isolation of mouse mammary epithelial subpopulations: a comparison of leading methods. J Mammary Gland Biol Neoplasia 2012, 17:91-97.

9. Van Keymeulen A, Rocha AS, Ousset M, Beck B, Bouvencourt G, Rock J, Sharma N, Dekoninck S, Blanpain C: Distinct stem cells contribute to mammary gland development and maintenance. Nature 2011, 479:189-193.

10. Boulanger CA, Wagner KU, Smith GH: Parity-induced mouse mammary epithelial cells are pluripotent, self-renewing and sensitive to TGF-beta1 expression. Oncogene 2005, 24:552-560.

11. Siwko SK, Dong J, Lewis MT, Liu H, Hilsenbeck SG, Li Y: Evidence that an early pregnancy causes a persistent decrease in the number of functional mammary epithelial stem cells--implications for pregnancy-induced protection against breast cancer. Stem Cells 2008, 26:3205-3209.

12. Britt KL, Kendrick H, Regan JL, Molyneux G, Magnay FA, Ashworth A, Smalley $\mathrm{MJ}$ : Pregnancy in the mature adult mouse does not alter the proportion of mammary epithelial stem/progenitor cells. Breast Cancer Res 2009, 11:R20.

13. Raafat A, Strizzi L, Lashin K, Ginsburg E, McCurdy D, Salamon D, Smith GH, Medina D, Callahn R: Effects of age and parity on mammary gland lesions and progenitor cells in the FVB/N-RC mice. PLOS One 2012, 7:e43624.

\section{doi:10.1186/bcr3414}

Cite this article as: Medina D: Pregnancy protection of breast cancer: new insights reveal unanswered questions. Breast Cancer Research 2013, 15:103. 